\title{
Antiphospholipid Antibodies, Brain Infarcts, and Cognitive and Motor Decline in Aging (ABICMA): Design of a Community-Based, Longitudinal, Clinical-Pathological Study
}

\author{
Zoe Arvanitakis $^{a}$ Robin L. Brey ${ }^{b}$ Jacob H. Rand ${ }^{c}$ Julie A. Schneider ${ }^{a}$ \\ Sue E. Leurgans ${ }^{a}$ Lei Yu ${ }^{a}$ Aron S. Buchman ${ }^{a}$ Konstantinos Arfanakis ${ }^{a} d$ \\ Debra A. Fleischman ${ }^{a}$ Patricia A. Boyle ${ }^{a}$ David A. Bennett ${ }^{a}$ Steven R. Levine ${ }^{e}$ \\ ${ }^{a}$ Rush Alzheimer's Disease Center, Rush University Medical Center, Chicago, III., ' Department of Neurology,

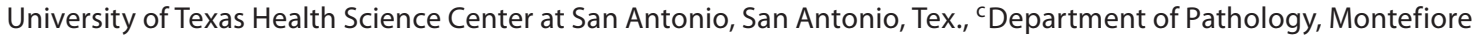 \\ Medical Center, Bronx, N.Y., dDepartment of Biomedical Engineering, Illinois Institute of Technology, Chicago, Ill., \\ and ${ }^{e}$ Department of Neurology, State University of New York Downstate Medical Center, Brooklyn, N.Y., USA
}

\section{Key Words}

Antiphospholipid antibodies • Anticardiolipin antibodies • Cerebrovascular disease $\cdot$ Annexins $\cdot$ Cognitive and motor function

\section{Abstract \\ The overall goal of the Antiphospholipid Antibodies, Brain Infarcts, and Cognitive and Motor Decline in Aging study is to test the hypothesis that antiphospholipid antibodies (aPL) are associated with an increased risk of pathologically prov- en brain infarcts and are related to cognitive and motor de- cline in aging. Putative biologic mechanisms underlying the association of aPL with infarcts and the relation of aPL with clinical outcomes of cognitive and motor impairment, in- cluding vascular and other processes, will be examined. The design of this longitudinal, clinical-pathologic study involves quantifying four aPL assays, and relating these to brain in- farcts, and to cognitive and motor decline. Vascular mecha- nisms assessed using antemortem magnetic resonance neuroimaging and postmortem neuropathology, as well as nonvascular mechanisms of inflammation and blood-brain barrier permeability alterations will be examined as plausi-}

ble mediators of the relation of aPL to cognitive and motor impairment. We will take advantage of antemortem biological specimens (longitudinally collected sera and plasma from which aPL, annexins, C-reactive protein, and matrix metalloproteinases will be quantified), and clinical, neuroimaging, and postmortem neuropathologic data from about 800 elderly, community-dwelling women and men who have agreed to brain autopsy at the time of death, participating in one of two ongoing studies of aging: the Religious Orders Study and the Memory and Aging Project.

Copyright $\odot 2012$ S. Karger AG, Basel

\section{Introduction}

Cerebrovascular disease is a leading cause of death and disability, and associated with two common consequences in older persons, cognitive and motor impairment. A growing number of studies implicate autoimmune processes in stroke, and the most commonly identified blood factor associated with immune-mediated stroke is antiphospholipid antibodies (aPL; table 1). Brain infarcts are among the most common and serious

\section{KARGER}

Fax +4161306 1234

E-Mail karger@karger.ch

www.karger.com
(C) 2012 S. Karger AG, Basel

$0251-5350 / 13 / 0402-0073 \$ 38.00 / 0$

Accessible online at:

www.karger.com/ned
Zoe Arvanitakis

Rush Alzheimer's Disease Center, Rush University Medical Center

600 S. Paulina, Suite 1022

Chicago, IL 60612 (USA) 
Table 1. Description of aPL antibody and related tests

\begin{tabular}{|c|c|}
\hline Test & Activity \\
\hline $\begin{array}{l}\text { Routine tests } \\
\text { aCL antibodies }\end{array}$ & $\begin{array}{l}\text { originally thought to measure } \\
\text { antibodies against this phospholipid, } \\
\text { but now understood to detect } \\
\text { phospholipid-binding proteins; } \\
\text { cardiolipin is present in intracellular } \\
\text { membranes }\end{array}$ \\
\hline $\begin{array}{l}\text { Anti- } \beta_{2} \text { GPI } \\
\text { antibodies }\end{array}$ & $\begin{array}{l}\text { measures antibodies against this } \\
\text { phospholipid }\end{array}$ \\
\hline LA test & $\begin{array}{l}\text { measures antibody-mediated } \\
\text { interference in assembly of blood } \\
\text { coagulation complexes on } \\
\text { phospholipid; surrogate test for } \\
\text { high-affinity/-avidity aPL antibodies }\end{array}$ \\
\hline $\begin{array}{l}\text { Other tests } \\
\text { aPS } \\
\text { antibodies }\end{array}$ & $\begin{array}{l}\text { measures antibodies bonding to this } \\
\text { phospholipid that may be more } \\
\text { biologically active than cardiolipin } \\
\text { because it is expressed on cytoplasmic } \\
\text { membranes }\end{array}$ \\
\hline Anti-domain 1 IgG & $\begin{array}{l}\text { detects antibodies that bind to this } \\
\text { aminoterminal domain of } \beta_{2} \text { GPI }\end{array}$ \\
\hline $\begin{array}{l}\text { Anti-annexin A5 } \\
\text { antibodies }\end{array}$ & $\begin{array}{l}\text { measures antibodies that bind to this } \\
\text { phospholipid-binding protein }\end{array}$ \\
\hline $\begin{array}{l}\text { Annexin A5 } \\
\text { resistance assay }\end{array}$ & $\begin{array}{l}\text { detects antibodies that bind with high } \\
\text { affinity and interfere with the } \\
\text { anticoagulant activity of this protein }\end{array}$ \\
\hline
\end{tabular}

manifestations of aPL. Prospective studies suggest that aPL increase risk for thrombo-occlusive events, including ischemic stroke (table 2) [1-3]. Only one study included both men and women and most research has focused on only one of four clinically used aPL, anticardiolipin antibodies $(\mathrm{aCL})$. The precise role of aPL as a group of autoantibodies in the pathogenesis of stroke in a wide range of patients and healthy individuals is unclear. In addition, specific underlying pathophysiologic mechanisms relating to aPL effects on the brain, in particular involving thrombosis, have yet to be elucidated. Preliminary data suggest potential roles by annexin A5 resistance, anti-annexin antibodies, and aPL binding to domain I (thrombogenic domain) of $\beta_{2}$-glycoprotein I [4].

The prevalence of aPL in aging and their association with stroke raise the possibility that aPL could also be associated with decline in cognitive and motor function, perhaps through an association with subclinical cerebrovascular disease. This is supported by some literature suggesting that aPL is independently associated with cognitive decline [5]. While the relation of aPL to cognitive function in aging is unclear, a recent international consensus statement concluded that further study is now warranted [6]. The relation of aPL to motor decline, the other common consequence of cerebrovascular disease in older persons, is also unclear.

The overall goal of the Antiphospholipid Antibodies, Brain Infarcts, and Cognitive and Motor Decline in Aging (ABICMA) study is to test the hypothesis that aPL are associated with an increased risk of pathologically proven brain infarcts and related to the two important clinical outcomes of cognitive and motor decline in communitydwelling older persons. We will investigate the significance of all four clinically used aPL. We will explore pathogenic mechanisms in aPL-related thrombosis, in particular that involving annexins. We will also examine the relation of aPL to cerebrovascular disease, including subclinical cerebrovascular disease assessed by antemortem neuroimaging and postmortem neuropathology, and the extent to which aPL are related to cognitive and motor impairment after controlling for this disease. This would suggest the existence of biologic mechanisms other than cerebrovascular disease linking aPL and cognitive and motor dysfunction. We will thus examine additional plausible factors in the causal pathway, in particular inflammation (assessed by C-reactive protein) and altered blood-brain barrier (BBB) permeability (assessed by matrix metalloproteinases), as these have been suggested to be mechanisms by which antibodies may be allowed to enter into the central nervous system and influence cellular function.

\section{Research Design and Methods}

\section{Overview of the Study Design}

ABICMA will test the hypothesis that aPL are associated with brain infarcts and cognitive and motor decline, and examine vascular and other mechanisms underlying these relations (fig. 1). This study, funded by the National Institutes of Health, began in September 2009. It takes advantage of two epidemiologic, longitudinal, clinical-pathologic cohort studies from the Rush Alzheimer's Disease Center in Chicago, Ill., USA. Previously collected and frozen blood specimens at baseline and follow-up will be used to relate aPL to clinical, pathologic, and other data (fig. 2). Sera are sent to the aPL Coordinating Laboratory at the University of Texas Health Sciences Center San Antonio for three aPL assays and other factors. Plasma are sent to the LA/Annexin Coordinating Laboratory in the Bronx, N.Y., USA, for assays of another aPL and annexins. All data are stored at the Rush Alzheimer's Disease Center. Uniform clinical evaluations are performed annually, from which data on change in cognitive and 
Table 2. Summary of large prospective cohort studies of aPL and thrombo-occlusive events

\begin{tabular}{|c|c|c|c|c|c|c|c|}
\hline PHS & Ginsburg et al. [1] & 1992 & $\mathrm{aCL}$ & $\begin{array}{l}\text { stroke } \\
\text { DVT or PE }\end{array}$ & $\begin{array}{l}\text { NS } \\
\text { RR } 5.3\end{array}$ & $\begin{array}{l}- \\
1.6,18.3\end{array}$ & $\begin{array}{l}5 \text { years, } \delta \\
5 \text { years, } \delta\end{array}$ \\
\hline HHS & Brey et al. [2] & 2001 & anti- $\beta_{2}$ GPI & $\begin{array}{l}\text { stroke } \\
\text { MI }\end{array}$ & $\begin{array}{l}\text { OR } 2.2 \\
\text { OR } 1.5 \\
\text { OR } 1.8 \\
\text { OR } 1.5\end{array}$ & $\begin{array}{l}1.5,3.4 \\
1.0,2.3 \\
1.2,2.6 \\
1.1,2.1\end{array}$ & $\begin{array}{l}15 \text { years, } \delta \\
20 \text { years, } \delta \\
15 \text { years, } \delta \\
20 \text { years, } \delta\end{array}$ \\
\hline FCOS & Janardhan et al. [3] & 2004 & $\mathrm{aCL}$ & stroke or TIA & $\begin{array}{l}\text { HR } 2.6 \\
\text { HR } 1.3\end{array}$ & $\begin{array}{l}1.3,5.4 \\
0.7,2.4\end{array}$ & $\begin{array}{l}11 \text { years, } ᄋ \\
11 \text { years, } \delta\end{array}$ \\
\hline
\end{tabular}

PHS = Physicians Health Study; HHS = Honolulu Heart Study; FCOS = Framingham Cohort and Offspring Study; DVT = deep vein thrombosis; $\mathrm{PE}=$ pulmonary embolism; $\mathrm{MI}=$ myocardial infarction; TIA = transient ischemic attack; NS = not significant; $\mathrm{RR}=$ relative risk; $\mathrm{OR}=$ odds ratio $\mathrm{HR}=$ hazard ratio; $\mathrm{CI}=$ confidence interval.

motor function are derived. Antemortem neuroimaging data are collected to assess infarcts and white matter hyperintensities. A standardized neuropathologic examination is conducted at the time of death, and provides data on the infarcts and on other variables, blinded to assay and clinical data. We estimate that blood specimens will be available in at least 800 persons for this study.

\section{Cohorts}

Specimens and data are derived from two epidemiologic cohort studies of cognitive and motor aging with essentially identical recruitment techniques, and a large overlap of identical specimen and data collection designed to facilitate analyses of risk factors for neurological conditions.

The Religious Orders Study (ROS) Core has been enrolling subjects since 1994 and is ongoing. All participants have consented to undergo annual clinical evaluations including cognitive and motor testing, a baseline blood draw, and brain donation at time of death. To date, the study has enrolled $\sim 1,200$ older Catholic clergy from $>40$ groups across the US, with a follow-up rate of $95 \%$. Blood specimens were collected from $>1,100$ persons, and a subset had one or more follow-up collections $(n>500)$. There have been $>550$ autopsies performed and the study autopsy rate exceeds $90 \%$ [7].

The Memory and Aging Project (MAP) has been enrolling subjects since 1997 and is ongoing. Participants have consented to undergo annual clinical evaluations including cognitive and motor testing, annual blood specimen collection, and brain, spinal cord, nerve and muscle donation at the time of death. To date, the study has enrolled $\sim 1,600$ older community-dwelling men and women living in $>40$ retirement communities or senior subsidized-housing facilities in the Chicagoland area. The follow-up rate is $\sim 85 \%$. There are $>1,500$ persons who had a blood specimen collected and many have had one or more follow-up collections ( $n=\sim 1,200$ ). With nearly 450 autopsies performed to date, the autopsy rate exceeds $80 \%$ [8].

aPL, Brain Infarcts and Cognitive and Motor Decline in Aging

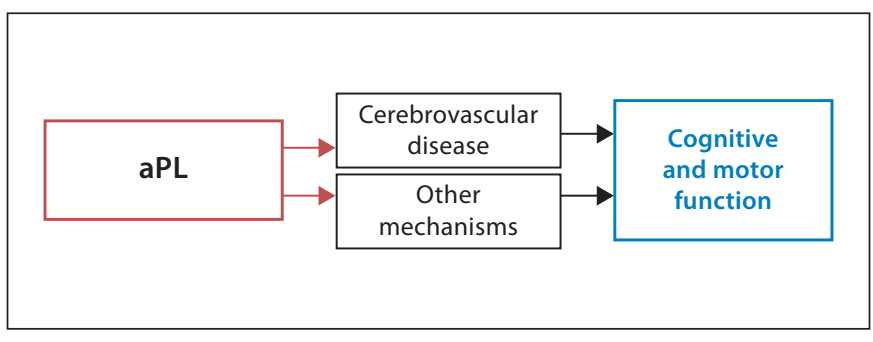

Fig. 1. Overall model relating aPL to outcomes of cognitive and motor decline. The relation of aPL to cognitive and motor function is mediated by cerebrovascular disease (top middle box) and other factors (bottom middle box).

\section{Available Clinical and Neuropathologic Data}

Clinical Data

Clinical data are collected at baseline and annually, from which change in cognitive and motor function will be derived for ABICMA. Participants of ROS and MAP undergo systematic, uniform evaluations, which include a medical history, physical examination focused, and neuropsychological testing. To date, there is an average of 6.8 years $(\mathrm{SD}=4.5)$ of annual follow-up data for ROS and MAP.

Cognitive data allow the documentation of the presence, severity and spectrum of cognitive impairment, and show relations with risk factors and adverse health outcomes [7, 8]. Neuropsychological tests assess a range of abilities emphasizing dissociable cognitive processes with different anatomic substrates commonly affected by aging. Individual tests (19 in ROS, 17 in MAP) are used to create a composite score of global cognition, as described elsewhere [9]. Further, composite scores of five cognitive domains are available, including perceptual speed, working memory, episodic memory, semantic memory, and visuospatial ability [9]. An experienced neuropsychologist, blinded to clinical data, reviews 
Fig. 2. Specimen and data transfer. RADC Lab $=$ Rush Alzheimer's Disease Center Laboratory; CRP = C-reactive protein; MMPs = matrix metalloproteinases.

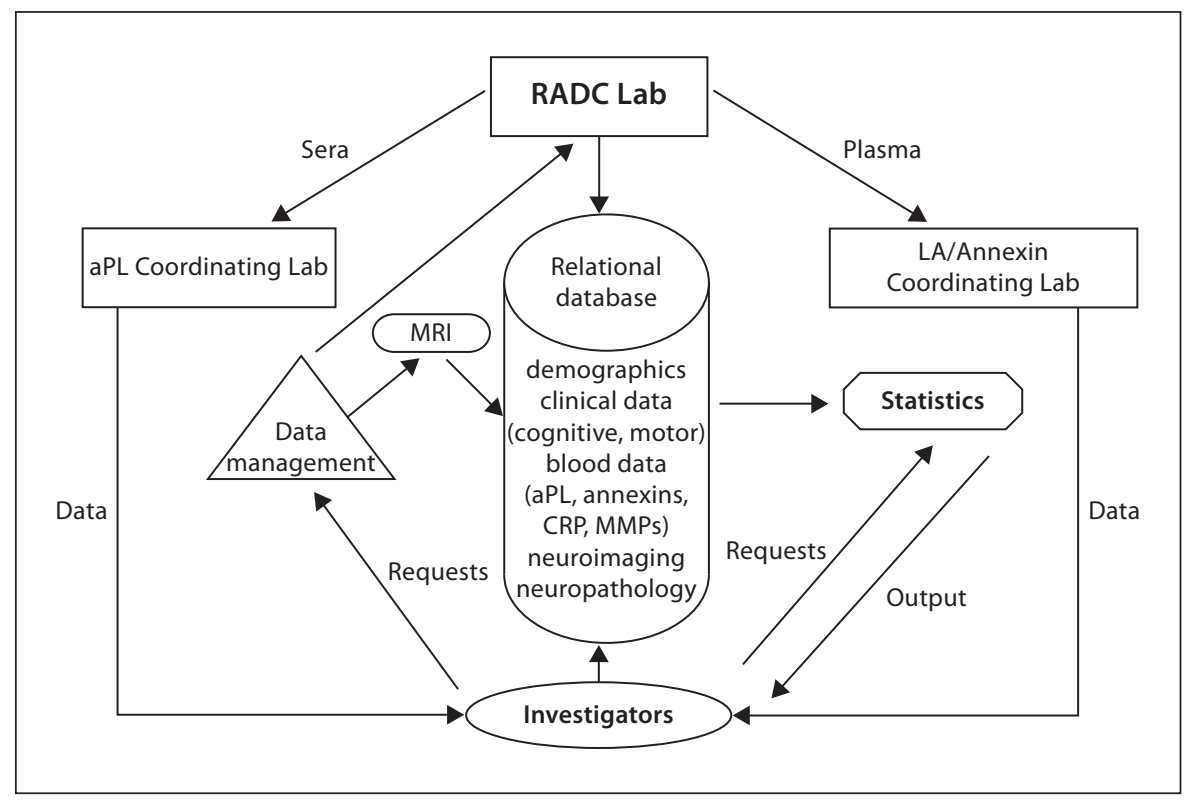

data and summarizes impairment in each domain. A 1-year interval between visits is long enough to allow measurable change in cognition. Diagnostic classification of cognitive status (dementia, mild cognitive impairment, cognitive impairment related to stroke) is conducted $[7,8]$.

Motor data are collected, from which level of and change in motor function are determined. These include components of standardized stroke and parkinsonism scales [8]. Additional motor data are available in MAP from which a composite global motor function score is derived [10]. Subcomponents include muscle strength (based on nine appendicular strength measures using dynamometers) and motor performance (based on nine upper and lower extremity measures).

Data on a range of vascular risk factors and conditions are available, including stroke, myocardial infarction, diabetes, hypertension, and hypercholesterolemia $[7,8]$.

Neuropathologic Data

A uniform evaluation, focused on common age-related pathologies, is performed by a board-certified neuropathologist blinded to clinical data. On macroscopic examination, the number, volume, location, and side of infarcts are recorded [11]. All grossly visualized and suspected infarcts are dissected for histologic examination. The presence and severity of atherosclerosis is assessed. The microscopic examination allows confirmation of the age of the infarcts. For identification of microscopic infarcts and other pathology, blocks are processed and stained. Location, side, and age of microscopic infarcts are determined [12]. The presence and severity of arteriolosclerosis are documented.

\section{Available Blood Specimens and Laboratory Data}

Blood is collected in serum separator and lavender top tubes, centrifuged, divided into aliquots, and stored at the Rush Alzheimer's Disease Center Laboratory in a $-80^{\circ} \mathrm{C}$ freezer. The base- line or first available specimen, and in a subset a second and third specimen collected at a later time point, are being used to measure markers of interest. A $0.5-\mathrm{ml}$ aliquot of serum is needed for three aPL assays, and an additional $0.5 \mathrm{ml}$ is needed for markers of inflammation (C-reactive protein) and BBB permeability (matrix metalloproteinase). Plasma $(0.5 \mathrm{ml})$ is used for annexins and one aPL assay. ABICMA is also taking advantage of existing laboratory data, including on inflammation and others.

\section{Quantification of Blood Measures}

The aPL Coordinating Laboratory is quantifying three serum aPLs: antibodies to aCL, $\beta_{2}$-glycoprotein I (anti- $\left.\beta_{2} \mathrm{GPI}\right)$, and antiphosphatidyl-serine (aPS). Results are interpreted blinded to clinical data. Commercial kits are used for aCL and aPS (Corgenics, Inc.), and anti- $\beta_{2}$ GPI (INOVA Diagnostics, Inc.), according to manufacturer's instructions. All tests are run in duplicate and if the variance is $>15 \%$, assays are repeated.

The LA/Annexin Coordinating Laboratory quantifies plasma measures: one aPL, lupus anticoagulant (LA), and all annexins. LA testing is performed using commercially available reagents on citrated plasma [13]. Annexin A5 resistance assays use a two-stage method [14]. Plasma is also assayed for anti- $\beta_{2}$ GPI IgG antibodies and anti-annexin A5 IgG and IgM (American Diagnostica, Inc.) [15].

Inflammation and BBB permeability may help elucidate separate, noncerebrovascular processes involved in aPL pathogenesis. Testing will be conducted at the aPL Coordinating Laboratory, using commercial kits for C-reactive protein (C-Reactive Protein Ultrasensitive ELISA, Calbiotech), and for matrix metalloproteinase 9 and matrix metalloproteinase tissue inhibitor (R\&D Systems, Inc.).

\section{Antemortem Neuroimaging of Vascular Processes}

aPL will be related to cerebrovascular disease abnormalities identified on brain MRI and to cognitive and motor function 
after controlling for these abnormalities, in a subset of subjects $(\sim 400)$. Data are collected using a 3T Philips scanner (Best, The Netherlands), located at the Brain Research Imaging Center, University of Chicago. Scans include a T1-weighted three-dimensional magnetization-prepared rapid acquisition gradient-echo (MP-RAGE) sequence with: $\mathrm{TE}=3.7 \mathrm{~ms}, \mathrm{TR}=8.1 \mathrm{~ms}$, flip angle $8^{\circ}, 181$ sagittal slices, slice thickness $1 \mathrm{~mm}$, acquired in-plane resolution $1 \times 1 \mathrm{~mm}$, parallel imaging; and a two-dimensional fast spin-echo $\mathrm{T} 2$-weighted fluid-attenuated inversion recovery (FLAIR) sequence with: $\mathrm{TE}=90 \mathrm{~ms}, \mathrm{TR}=9 \mathrm{~s}$, inversion time $\mathrm{TI}=2.5 \mathrm{~s}, 35$ axial slices, slice thickness $4 \mathrm{~mm}$, acquired in-plane resolution $0.86 \times 1.12 \mathrm{~mm}$, and parallel imaging. Total acquisition time is $\sim 10 \mathrm{~min}$.

Post-processing of data provide the number/volume/location of infarcts and WMH. MP-RAGE and FLAIR image volumes are aligned using rigid body registration. Infarcts are manually segmented (http://afni.nimh.nih.gov/afni) [16]. WMH are segmented automatically based on a support vector machine learner (WMLS, SBIA, University of Pennsylvania) [17]. We then register a human brain atlas to the T1-weighted volume of each subject, and transfer labeled white matter regions to the space of individual subjects. Location of lesions is automatically recorded by identifying labels that overlap with segmented lesions.

\section{Data Management}

Blood specimen data are linked to clinical, neuroimaging, and neuropathologic data using a relational database (fig. 2). Access is secured and checks ensure data integrity. Customized programs score and summarize data, and provide automatically updated reports, available on a secure SSL website (Apache Tomcat Web Server 6.0.14).

\section{Data Analyses}

We first provide descriptive information on subjects enrolled in ABICMA to date, their clinical and neuropathologic characteristics, and preliminary blood data. We next present power calculations for the main hypotheses of the study.

\section{Results}

\section{Subjects}

Of $>2,000$ eligible subjects to date, ABICMA will include approximately 800 alive or deceased subjects for whom at least one frozen serum specimen is available for aPL quantification. Blood specimens from two additional time points, proximate to death and another point between the first and last measurement, will be used to assess persistence of aPL positivity and altered annexins. About 1,600 persons have at least one follow-up serum and plasma specimen. To date, blood data have been collected in deceased subjects only, in order to examine one of the main hypothesis, namely the relation of aPL to pathologically proven brain infarcts. Here, we present data on the first 538 subjects.

aPL, Brain Infarcts and Cognitive and Motor Decline in Aging
Table 3. Demographic characteristics of 538 subjects included in ABICMA to date

\begin{tabular}{|c|c|c|c|}
\hline & $\begin{array}{l}\text { ROS } \\
(\mathrm{n}=178)\end{array}$ & $\begin{array}{l}\text { MAP } \\
(\mathrm{n}=360)\end{array}$ & $\begin{array}{l}\text { Total }^{1} \\
(\mathrm{n}=538)\end{array}$ \\
\hline Age $\pm S D$, years $^{2}$ & $83.4 \pm 7.4$ & $84.6 \pm 6.1$ & $84.2 \pm 6.5$ \\
\hline Male, n (\%) & $60(33.7)$ & $128(35.6)$ & $188(34.9)$ \\
\hline White, n (\%) & $173(97.7)$ & $352(97.8)$ & $525(97.8)$ \\
\hline Education $\pm S D$, years & $17.9 \pm 3.4$ & $14.4 \pm 2.8$ & $15.5 \pm 3.5$ \\
\hline
\end{tabular}

${ }^{1} \mathrm{n}=$ Number of subjects. Deceased and autopsied subjects who had frozen blood specimens available and in whom aPL data have been collected to date. Because studies are ongoing, additional subjects will be eligible for ABICMA in the future.

${ }^{2}$ Age at time of first aPL measurement.

Table 4. Cognitive and motor data

Total $(\mathrm{n}=538)$

Cognitive data

Global cognitive function score $\quad-0.29(0.87)$

Perceptual speed score $\quad-0.51(1.03)$

Working memory score $\quad-0.14(0.85)$

Episodic memory score $\quad-0.31(1.08)$

Semantic memory score $\quad-0.25(0.94)$

Visuospatial ability score

$-0.17(0.92)$

Mild cognitive impairment, n (\%)

$187(34.9)$

\section{Motor data}

Global parkinsonian signs score

$14.6(10.5)$

Gait disturbance score

$28.9(19.7)$

Bradykinesia score

$16.3(15.0)$

Rigidity score

$8.5(14.7)$

Tremor score

$4.1(7.2)$

Global motor function score ${ }^{1}$

Muscle strength score

$0.75(0.24)$

Motor performance score

$0.80(0.26)$

$0.74(0.26)$

Data are presented as mean (SD) scores, unless otherwise specified, at time of first aPL measurement.

${ }^{1}$ Data available only in the MAP cohort.

\section{Demographic, Clinical, and MRI Data}

Basic demographic data are shown in table 3. The mean age at time of the first aPL measurement was 84.2 years $(S D=6.5)$ and at death was 88.7 years $(S D=6.4)$. Selected clinical data, including cognitive and motor data (table 4), vascular factors, medications, and laboratory data, are presented (table 5). MRI scans were performed in $17 / 538$ subjects to date (fig. 3 ). 
Table 5. Clinical characteristics

\begin{tabular}{|c|c|}
\hline & Total $(\mathrm{n}=538)$ \\
\hline \multicolumn{2}{|l|}{ Vascular factors } \\
\hline \multicolumn{2}{|l|}{ Vascular conditions, $\mathrm{n}(\%)$} \\
\hline Stroke & $112(21)$ \\
\hline Myocardial infarction & $133(25)$ \\
\hline Claudication & $140(26)$ \\
\hline \multicolumn{2}{|l|}{ Vascular risk factors, $\mathrm{n}(\%)$} \\
\hline Diabetes & $118(22)$ \\
\hline Hypertension & $370(69)$ \\
\hline Smoking (ever) & $175(33)$ \\
\hline \multicolumn{2}{|l|}{ Other vascular factors, mean $\pm S D$} \\
\hline Systolic BP proximate to death & $128 \pm 21$ \\
\hline Diastolic BP proximate to death & $81 \pm 11$ \\
\hline Body mass index proximate to death & $26.0 \pm 5.1$ \\
\hline \multicolumn{2}{|l|}{ Medications, $n(\%)$} \\
\hline Aspirin & $388(72)$ \\
\hline Amiodarone & $111(21)$ \\
\hline Digoxin & $85(16)$ \\
\hline Statin & $214(40)$ \\
\hline Antihypertensive & $438(81)$ \\
\hline Insulin & $37(7)$ \\
\hline Oral hypoglycemic & $81(15)$ \\
\hline \multicolumn{2}{|l|}{ Laboratory factors ${ }^{1}$, mean $\pm S D$} \\
\hline \multicolumn{2}{|l|}{ Lipid profile } \\
\hline Total cholesterol & $187 \pm 40$ \\
\hline LDL & $104 \pm 33$ \\
\hline HDL & $54 \pm 16$ \\
\hline Hemoglobin $\mathrm{A}_{1} \mathrm{C}$ & $6.0 \pm 0.6$ \\
\hline
\end{tabular}

Data are derived from all study evaluations (coded as present if identified at least once across the study), unless otherwise specified. $\mathrm{n}=$ Number of subjects.

${ }^{1}$ At time of first aPL measurement or first available data.

\section{Neuropathologic Data}

Data on 531/538 (99\%) deceased and autopsied subjects are currently available. Brain infarcts (macroscopic or microscopic) are present in 258/531 (49\%) of subjects (table 6; fig. 4). Large and small vessel pathology is also common.

\section{aPL and Annexin Measurements}

Four aPL measures have been quantified (aCL, anti$\beta_{2}$ GPI, and aPS, LA) using the first sample collected (table 7). The mean time interval from this measurement to death is $4.6(\mathrm{SD}=2.5)$ years. The overall aPL positivity (positivity in any of four aPL) in this first measurement is $24.4 \%$. Follow-up measures proximate to death have been quantified in $418 / 538$ subjects, with a mean time interval to death of $0.8(\mathrm{SD}=0.7)$ years. The overall aPL positivity
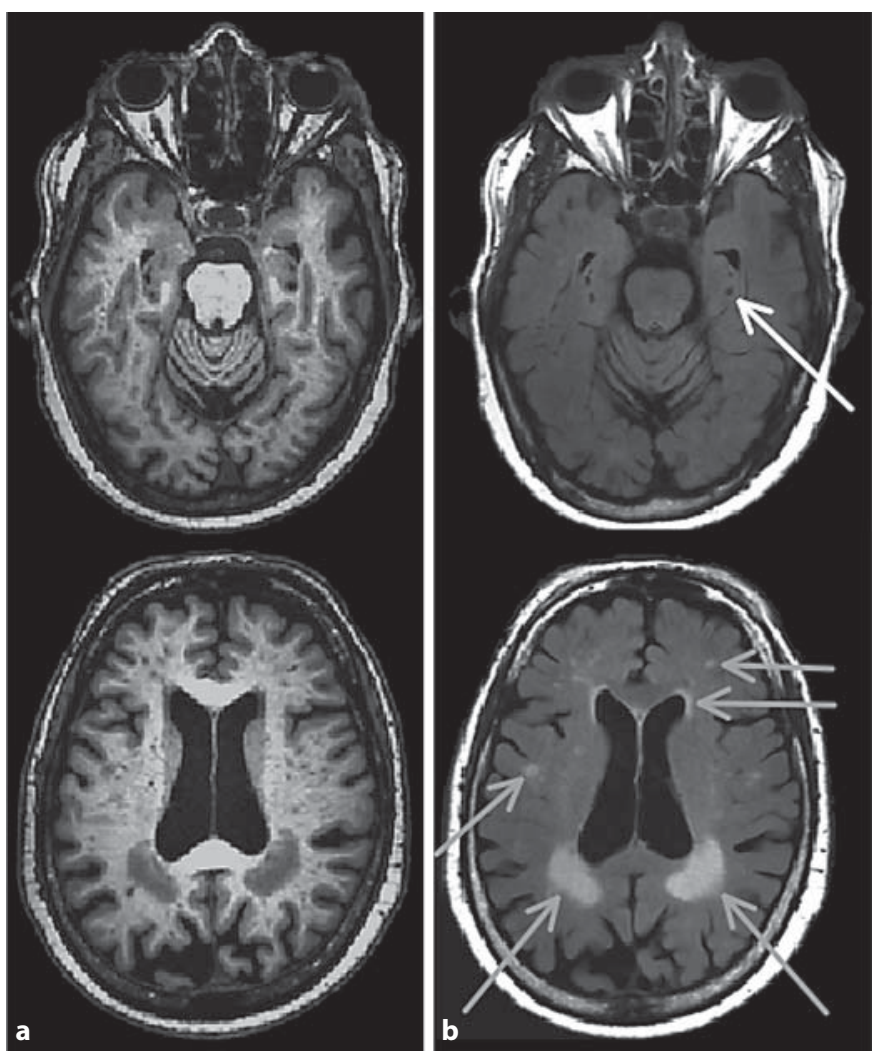

Fig. 3. Antemortem brain MRI scan demonstrating cerebrovascular disease in vivo. $\mathrm{T}_{1}$-weighted MP-RAGE (a) and $\mathrm{T}_{2}$-weighted FLAIR (b) images of two slices of a MAP participant, demonstrating examples of infarcts (white arrow) and white matter hyperintensities (gray arrows).

proximate to death is $31.1 \%$, suggesting a relation of increasing positivity with age. The persistence of aPL positivity (positivity identified at both time points) is $75 \%$, suggesting that positivity may change over time and underscoring the importance of collecting longitudinal data. Descriptive data on annexins are also shown in table 7.

\section{Power}

Different approaches are used for modeling the presence of infarcts (binary cross-sectional data) and cognitive or motor decline (continuous longitudinal data). In examining the association of overall aPL positivity with the presence of infarct, the projected power depends on the sample size, the proportion of aPL positivity, the baseline probability of infarct, and the effect size quantified by the odds ratio [18]. Preliminary data suggests that about 25\% of subjects are aPL-positive. Assuming a baseline probability of infarct of 0.45 , a sample size of 800 will have $82 \%$ 


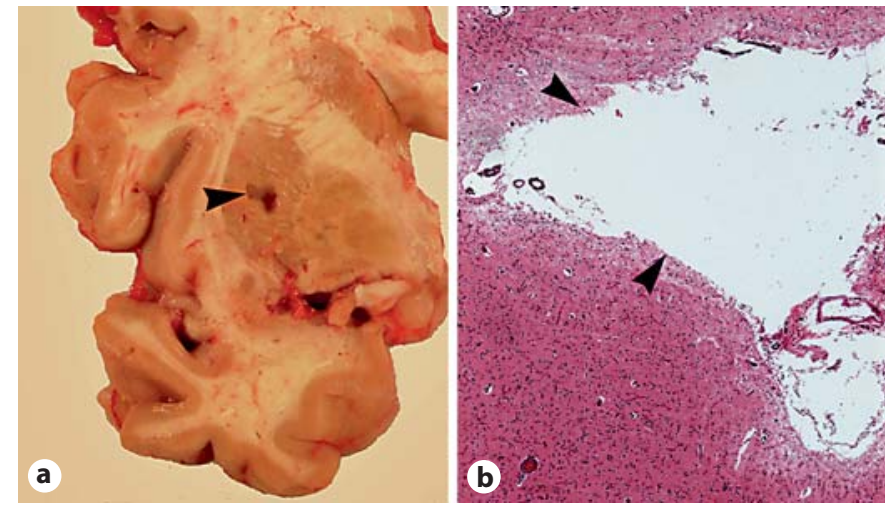

Fig. 4. Postmortem neuropathology demonstrating cerebrovascular disease. a Chronic infarct from a fresh brain slice, with an irregular-shaped cystic cavity in the anterior putamen (arrowhead). b Microscopic confirmation of the same infarct (arrowheads), showing a cystic cavity with loss of neural tissue and viable vessels in the periphery of the cavity. HE. $\times 40$.

power to detect an odds ratio of 1.60 at an $\alpha$ level of 0.05 (table 8). For longitudinal data analysis, random coefficient models will be used to examine the relation of aPL positivity with the rate of decline in cognitive (motor) function. In these models, the point estimate, when negative, indicates the additional amount of cognitive (motor) decline, per year, for subjects with aPL positivity. Assumptions for the power are based on current data and previous analysis results. To date, among individuals with aPL data, the average number of annual visits is 7 years, and the variances associated with random slopes and residuals are 0.01 and 0.05 . As shown in table 9 , at $\alpha$ level of 0.05 a sample size of 800 will have $81 \%$ power to detect a 0.025 unit of steeper decline in cognitive (motor) function.

\section{Discussion}

ABICMA is a longitudinal, clinical-pathologic study testing the hypothesis that aPL are associated with brain infarct risk and two most common consequences of cerebrovascular disease, cognitive and motor decline. The study will provide a comprehensive aPL portfolio on a large cohort of $\sim 800$ community-dwelling older subjects followed clinically with cognitive and motor change data, and in whom brain autopsy is conducted. Further, this study will examine putative biologic mechanisms underlying associations of aPL with neuropathologic and clinical outcomes. In particular, ABICMA will examine the role of annexins in the relation of aPL to infarct pathol-
Table 6. Neuropathologic characteristics

Total

$(\mathrm{n}=531)$

\begin{tabular}{lc} 
Brain infarcts, $n(\%)$ & \\
Any infarct present (macro- or microscopic) & $313(59)$ \\
Macroscopic infarcts present & $256(48)$ \\
$\quad$ Number of infarcts & \\
$\quad$ One & 109 \\
More than one & 147 \\
Location, $\mathrm{n}$ & \\
$\quad$ Cortical & 137 \\
$\quad$ Subcortical & 193 \\
$\quad$ Brainstem or cerebellum & 36 \\
Microinfarct present, $\mathrm{n}(\%)$ & $185(35)$ \\
$\quad$ Number of microinfarcts & 102 \\
$\quad$ One & 83 \\
$\quad$ More than one & \\
Location, $\mathrm{n}$ & 97 \\
$\quad$ Cortical & 128 \\
$\quad$ Subcortical & 6 \\
$\quad$ Brainstem or cerebellum & \\
\hline Vessel pathology ${ }^{1}, n(\%)$ & $228(43)$ \\
Atherosclerosis & $206(39)$ \\
Arteriosclerosis &
\end{tabular}

\footnotetext{
${ }^{1}$ Moderate or more severe.
}

Table 7. aPL and annexin measures

\begin{tabular}{lll}
\hline & $\begin{array}{l}\text { Time point } 1 \\
(\mathrm{n}=538)\end{array}$ & $\begin{array}{l}\text { Time point } 2 \\
\text { proximate to } \\
\text { death) }(\mathrm{n}=418)\end{array}$ \\
\hline $\begin{array}{ll}\text { aPL positivity, } n(\%) \\
\text { aCL }\end{array}$ & $131(24.4)$ & $130(31.1)$ \\
$\quad$ IgG & $24(5)$ & $36(9)$ \\
$\quad$ IgM & $85(16)$ & $79(19)$ \\
Anti- $\beta_{2}$ GPI & $10(2)$ & $10(2)$ \\
$\quad$ IgG & $29(5)$ & $21(5)$ \\
IgM & $23(4)$ & $21(5)$ \\
aPS & $41(8)$ & $36(9)$ \\
$\quad$ IgG & $6(1)$ & $6(1)$ \\
IgM & & \\
LA positivity & $59(11)$ & $33(8)$ \\
Annexin positivity, $n(\%)$ & $33(6)$ & $12(3)$ \\
Annexin A5 resistance & & \\
Anti- $\beta_{2}$ GPI IgG & $13(2)$ & $10(2)$ \\
Antiannexin A5 & $12(2)$ & $8(2)$ \\
$\quad$ IgG & & \\
IgM & &
\end{tabular}


Fig. 5. Overall study design for ABICMA.

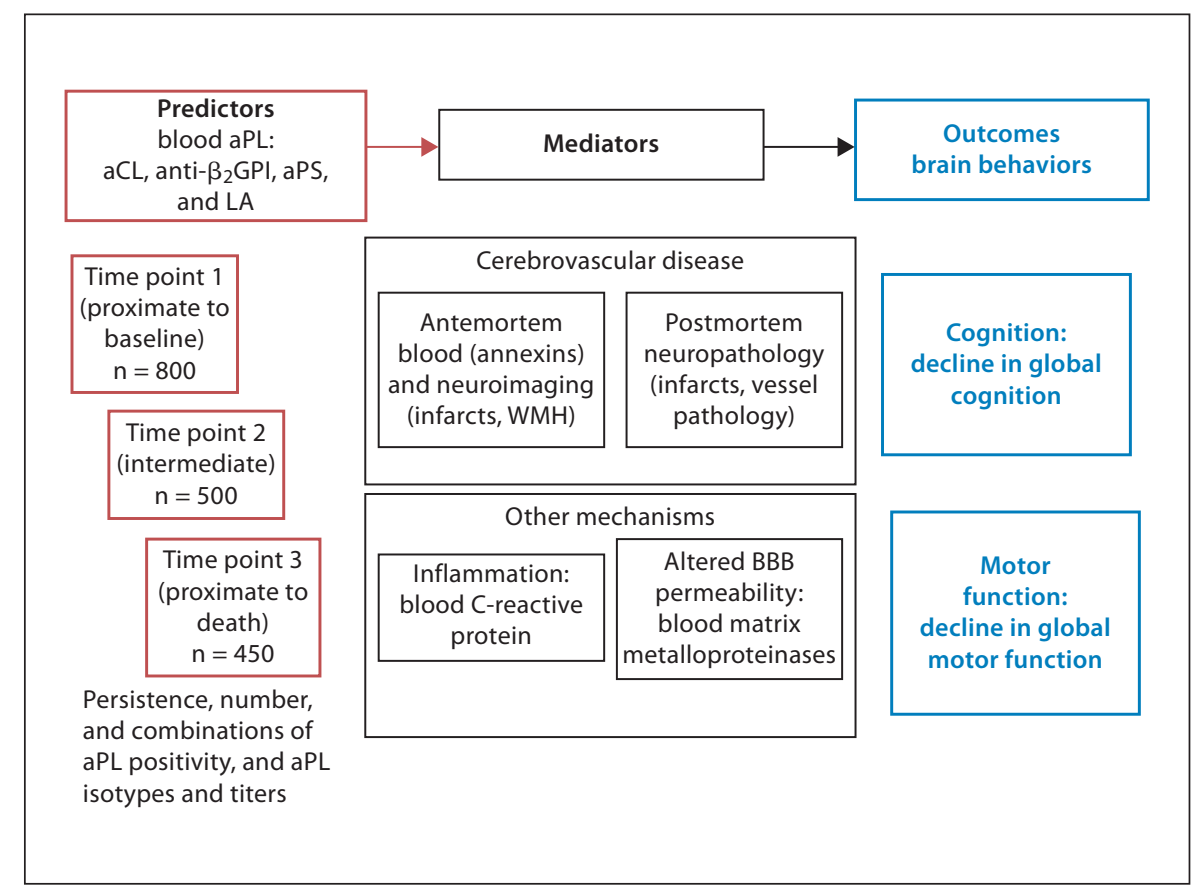

Table 8. Power for infarct outcome

\begin{tabular}{lllll}
\hline $\mathrm{n}$ & aPL positivity & $\mathrm{p}_{0}$ & OR & Power \\
\hline \multirow{2}{*}{650} & $25 \%$ & 0.45 & 1.60 & 0.74 \\
& & & 1.50 & 0.61 \\
\multirow{2}{*}{800} & \multirow{2}{*}{$25 \%$} & \multirow{2}{*}{0.45} & 1.40 & 0.46 \\
& & & 1.50 & 0.82 \\
& & & 1.40 & 0.70 \\
1,000 & $25 \%$ & 0.45 & 1.60 & 0.54 \\
& & & 1.50 & 0.79 \\
& & & 1.40 & 0.63 \\
\hline
\end{tabular}

ogy. Also, mechanisms linking aPL to clinical outcomes of cognitive and motor impairment will be explored, including vascular processes determined using antemortem MRI and postmortem neuropathology, as well as nonvascular processes involving inflammation and altered BBB permeability (fig. 5).

aPL are present in a third of persons in their eighth decade, and are associated with significant disability and death [3]. Cerebrovascular disease is the most common among neurological presentations, and second most common presentation overall [19]. While studies in young persons have consistently shown an association with ischemic stroke, data in older persons is mixed [20]. Only three prospective epidemiologic studies have directly examined aPL and stroke, and only one aPL antibody was tested and only at a single time point (see table 2). One study of male physicians was negative, but power may have been limited [1]. Another study showed an odds of stroke of 1.5 [2]. In a third study, women but not men had an increased risk of stroke [3]. Additional clinical trial data suggest that both aCL and LA, rather than either alone, are associated with stroke [21]. aPL research should consider a panel of aPL, particularly since two other clinical tests have since emerged as potentially important (anti- $\beta_{2}$ GPI and aPS). Further, research on persistence of aPL positivity as a prognostic factor, including anti- $\beta_{2}$ GPI, is needed $[6,21]$.

Although aPL are linked to the clinical manifestation of cerebrovascular disease and are used in clinical practice as stroke-predictive biomarkers, there is a paucity of data on aPL and pathologically proven brain infarcts, the underlying cause of most clinical strokes. Prior studies' limitations may be addressed by research using brain tissue with definitive identification of infarcts, including microscopic infarcts, which elude identification by currently available neuroimaging technology $[12,22]$. Case reports with brain tissue data showed perivascular inflammation and amyloid- $\beta$ deposition in vessels, while others found changes suggestive of a non-inflammatory 


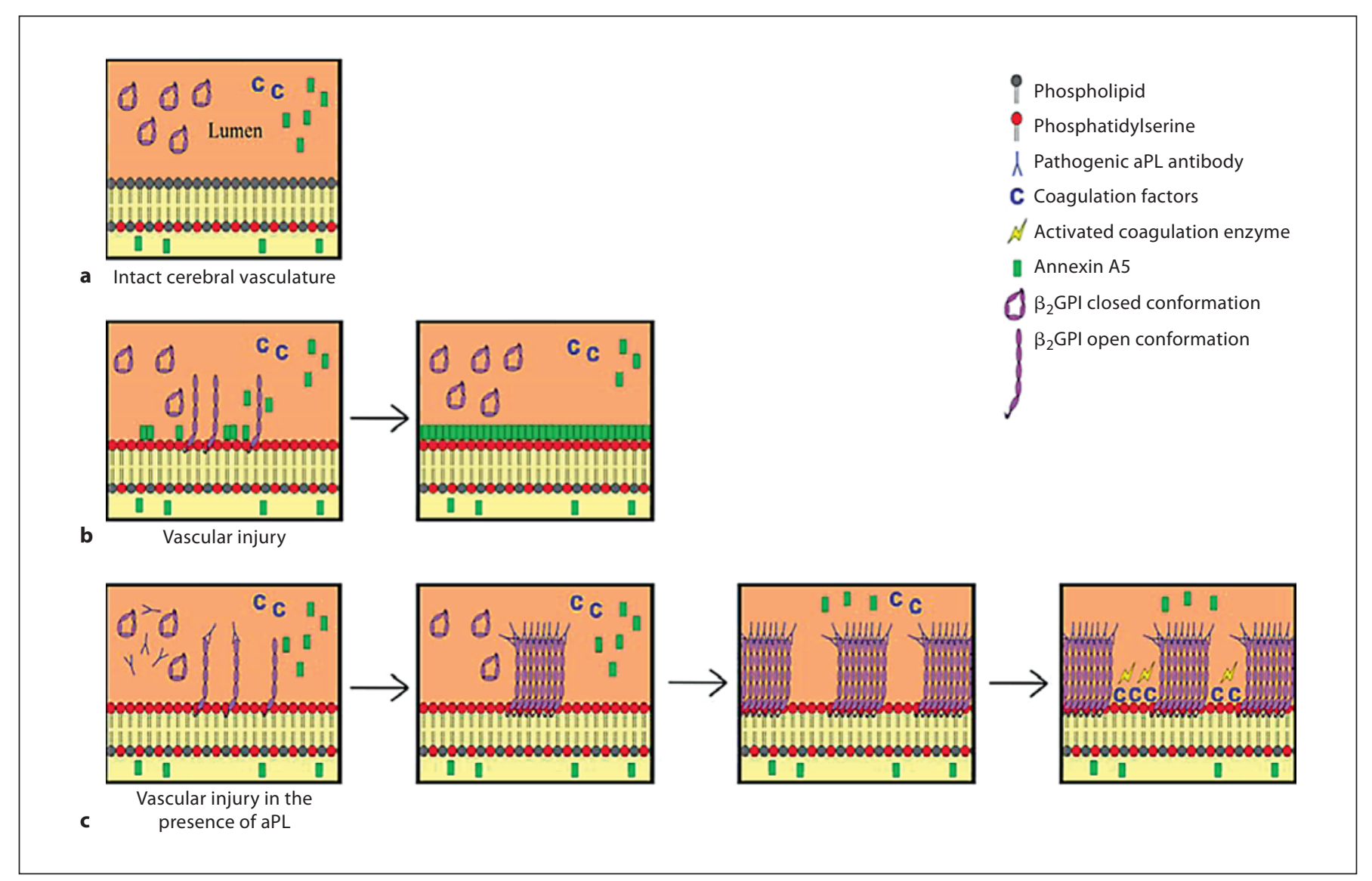

Fig. 6. Multistep hypothesis for aPL-mediated infarct involving annexin resistance. a Intact cerebral vasculature is thromboresistant. $\beta_{2}$ GPI circulates in the circular conformation. b Vascular injury in the absence of aPL antibodies: phosphatidylserine becomes exposed, with capacity to stimulate thrombotic response, and is available for binding to competing moieties ( $\beta_{2} \mathrm{GPI}$, annexin A5, and coagulation factors). A5, which is expressed inside the endothelium and circulating in the microenvironment over it, has the highest affinity because of its two-dimensional crystalli- zation and multivalency. A5 'outcompetes' the other moieties and covers the injured surface, restoring thromboresistance. c Vascular injury in the presence of aPL antibodies: binding of $\beta_{2}$ GPI requires conformational change that snaps it open and exposes the domain 1 epitope. This leads to formation of high-affinity immune complexes, which 'outcompetes' A5 for binding and leaves insufficient space for formation of ordered crystals of A5. Gaps in coverage of phosphatidylserine become occupied by coagulation factors that stimulate thrombosis.

Table 9. Power for longitudinal cognitive and motor outcomes

\begin{tabular}{|c|c|c|c|c|c|c|c|}
\hline $\mathrm{n}$ & $\begin{array}{l}\text { aPL } \\
\text { positivity }\end{array}$ & $\begin{array}{l}\text { Annual } \\
\text { visits, } \mathrm{n}\end{array}$ & $\begin{array}{l}\mathrm{G}(2,2) \text { variance } \\
\text { of random slope }\end{array}$ & $\begin{array}{l}\text { Residual } \\
\text { variance }\end{array}$ & $\begin{array}{l}\text { Type-I } \\
\text { error } \alpha\end{array}$ & $\begin{array}{l}\text { Point } \\
\text { estimate }\end{array}$ & Power \\
\hline 650 & $25 \%$ & 7 & 0.01 & 0.05 & 0.05 & $\begin{array}{l}-0.025 \\
-0.030\end{array}$ & $\begin{array}{l}0.72 \\
0.86\end{array}$ \\
\hline 800 & $25 \%$ & 7 & 0.01 & 0.05 & 0.05 & $\begin{array}{l}-0.025 \\
-0.030\end{array}$ & $\begin{array}{l}0.81 \\
0.92\end{array}$ \\
\hline 1,000 & $25 \%$ & 7 & 0.01 & 0.05 & 0.05 & $\begin{array}{l}-0.025 \\
-0.030\end{array}$ & $\begin{array}{l}0.88 \\
0.97\end{array}$ \\
\hline
\end{tabular}


vasculopathy [23]. Further, in 150 patients who came to autopsy, aPL were relatively common but not associated with vasculitis [24]. Discrepancies in findings may be due to a variety of factors, including case selection and differential effects of aPL.

Given the relation of aPL to stroke, these antibodies may be associated with the two most common clinical consequences of cerebrovascular disease in aging, cognitive and motor decline. While several studies have found a relation to dementia or cognitive impairment, the literature has focused on case-control series, mostly using a cross-sectional design [22]. Few longitudinal studies of aPL and change in cognition are published, all in systemic lupus erythematosus and controls, and results suggest associations with cognitive decline, particularly in psychomotor speed and working memory $[5,25,26]$. Further, the possibility that neurologic effects of aPL may be independent of the actual disease state of lupus has been raised. While there is relatively little data, an international consensus statement calls for further study to determine whether aPL affect cognition [6]. Further, the role of aPL in the other important neurological condition of aging, motor decline, is uncertain and warrants further study.

Mechanisms linking aPL to cerebrovascular disease have been unclear. This may be explained, at least in part, by heterogeneity among aPL [6]. Also, research suggests that both aPS and $\beta_{2}$ GPI antibodies improve specificity of the aPL antibody syndrome over aCL alone. Emerging data, including from animal and human imaging studies, point toward vascular processes and thrombosis in particular, as important plausible mechanisms [27]. Antibodies have been proposed to interfere with endogenous anticoagulant mechanisms, such as the annexin A5 anticoagulant shield. Indeed, human tissue studies of persons with aPL show reduction of annexin A5 on cell surfaces including of endothelial cells, and morphologic evidence using atomic force microscopy shows aPL disruption of annexin A5 crystallization [14, 28]. The annexin mechanism has been confirmed, and the assay for annexin A5 resistance has been validated [15]. We will examine annexins as a mechanism for thrombosis that would manifest itself as pathologically-proven brain infarct (fig. 6).

Additional data from cell, animal, and human studies, suggest that other vascular mechanisms, including ones without evidence of brain infarct, as well as non-vascular mechanisms may be at play in aPL pathogenesis. MRI studies have shown both large and small infarcts, $\mathrm{WMH}$, as well as atrophy $[22,29]$. Further, evidence points to aPL having a range of effects, including BBB breakdown, in- flammation, extravasation of blood proteins, including aCL and anti- $\beta_{2}$ GPI, which may then exert direct cellular dysfunction, neurodegeneration, and others $[27,30]$. We will examine some of these mechanisms. The mechanistic hypothesis concerns the antemortem and postmortem indicators of cerebrovascular disease (using MRI and neuropathology) as mediators of the association of aPL with impaired cognitive and motor function (fig. 5). The study design will allow us to examine for subclinical cerebrovascular disease, which is thought to be a much more common problem than stroke, which itself may be seen as only the 'tip of the iceberg'. In order to explore potential non-cerebrovascular mechanisms, we will assess inflammation (using C-reactive protein) and altered BBB permeability (matrix metalloproteinase), and whether the relation of aPL to cognitive and motor impairment is attenuated when accounting for these.

Strengths of ABICMA include being the only epidemiologic study, to our knowledge, linking aPL to pathologically-proven brain infarct and cognitive and motor function. The study takes advantages of specimens and data from two community-based cohorts of both older women and men with high autopsy rates. Systematically collected annual clinical data and postmortem vascular neuropathology data provide outcome summary measures. The assessment of aPL is comprehensive, including a panel of four aPL, three of which quantify two isotypes (IgG and IgM). We will examine persistence, number and combinations of aPL positivity, and aPL isotypes and titers. Putative biologic mechanisms will be elucidated, specifically annexins and other vascular and non-vascular mechanisms, including subclinical cerebrovascular disease assessed using antemortem MRI and postmortem neuropathology.

There are also several limitations. A challenge concerns the variability in laboratory measurements. Given the expertise and experience of the two laboratories used in ABICMA, we are confident that we can adequately address this challenge. There are also limitations in the definition of aPL. While we will be using the recommended cutoffs for aPL positivity, based on the manufacturers guidelines and literature, it is possible that only higher titers are important [1]. We will be able to address this with further exploratory analyses. Further, our chosen definition will allow a more direct comparison to the other major epidemiologic studies to date.

A critical barrier to progress in aPL research is accessibility to a large cohort of older persons, with data on aPL and other potential pathogenic markers, longitudinal measures of cognitive and motor function, and objective 
data on cerebrovascular disease including subclinical disease. Although ABICMA promises to overcome this barrier, improve scientific knowledge in the field, and have the potential to change clinical practice as aPL are modifiable vascular factors, further research is needed in the field. Findings from ABICMA will need to be replicated in other cohorts. Further, research on neuropathologic measures of WMH identified in neuroimaging would help to expand the examination of aPL and cognitive and motor outcomes after controlling for a wider range of cerebrovascular disease. Other vascular and non-vascular mechanisms will need to be explored. Finally, the risk-benefit ratio of testing and treating aPL in cerebrovascular disease, and cognitive and motor decline in aging will need to be determined.

\section{Acknowledgments}

The authors thank the participants of the Religious Orders Study and the Memory and Aging Project.

ABICMA is funded by the National Institutes of Health (R01 HL96944, R01 AG040039) and takes advantage of several other grants (P30 AG10161, R01 AG15819, R01 AG17917, R01 AG24480) and the Illinois Department of Public Health.

The authors thank Patricia Padilla at the aPL Coordinating Laboratory, Dr. Xuan Wu Xiao at the LA/Annexin Coordinating Laboratory for quantification of blood measures, and the Rush Alzheimer's Disease Center staff.

\section{References}

1 Ginsburg KS, Liang MH, Newcomer L, Goldhaber SZ, Schur PH, Hennekens $\mathrm{CH}$, Stampfer MJ: Anticardiolipin antibodies and the risk for ischemic stroke and venous thrombosis. Ann Intern Med 1992;117:9971002.

2 Brey RL, Abbott RD, Curb JD, Sharp DS, Ross GW, Stallworth CL, Kittner SJ: Beta(2)glycoprotein 1-dependent anticardiolipin antibodies and risk of ischemic stroke and myocardial infarction: the Honolulu Heart Program. Stroke 2001;32:1701-1706.

3 Janardhan V, Wolf PA, Kase CS, Massaro JM, D’Agostino RB, Franzblau C, Wilson PWF: Anticardiolipin antibodies and risk of ischemic stroke and transient ischemic attack. The Framingham Cohort and Offspring Study. Stroke 2004;35:736-741.

-4 Rand JH, Wu XX, Andree HA, Lockwood CJ, Guller S, Scher J, Harpel PC: Pregnancy loss in the antiphospholipid-antibody syndrome - a possible thrombogenic mechanism. N Engl J Med 1997;337:154-160.

5 McLaurin EY, Holliday SL, Williams P, Brey RL: Predictors of cognitive dysfunction in patients with systemic lupus erythematosus. Neurology 2005;64:297-303.

-6 Miyakis S, Lockshin MD, Atsumi T, Branch DW, Brey RL, Cervera R, Derksen RH, DE Groot PG, Koike T, Meroni PL, Reber G, Shoenfeld Y, Tincani A, Vlachoyiannopoulos PG, Krilis SA: International consensus statement on an update of the classification criteria for definite antiphospholipid syndrome (APS). J Thromb Haemost 2006;4: 295-306.

7 Bennett DA, Schneider JA, Arvanitakis Z, Wilson RS: Overview and findings from the Religious Orders Study. Curr Alzheimer Res 2012;9:628-645.
8 Bennett DA, Schneider JA, Buchman AS, Barnes LL, Boyle PA, Wilson RS: Overview and findings from the Rush Memory and Aging Project. Curr Alzheimer Res 2012;9: 646-663.

-9 Wilson RS, Beckett LA, Barnes LL, Schneider JA, Bach J, Evans DA, Bennett DA: Individual differences in rates of change in cognitive abilities of older persons. Psychol Aging 2002;17:179-193.

10 Buchman AS, Boyle PA, Wilson RS, Bienias JL, Bennett DA: Physical activity and motor decline in older persons. Muscle Nerve 2007; 35:354-362.

11 Schneider JA, Wilson RS, Cochran EJ, Bienias JL, Arnold SE, Evans DA, Bennett DA: Relation of cerebral infarctions to dementia and cognitive function in older persons. Neurology 2003;60:1082-1088.

12 Arvanitakis Z, Leurgans SE, Barnes LL, Bennett DA, Schneider JA: Microinfarct pathology, dementia, and cognitive systems. Stroke 2011;42:722-727.

13 Pengo V, Tripodi A, Reber G, Rand JH, Ortel TL, Galli M, De Groot PG; Subcommittee on Lupus Anticoagulant/Antiphospholipid Antibody of the Scientific and Standardisation Committee of the International Society on Thrombosis and Haemostasis: Update of the guidelines for lupus anticoagulant detection. J Thromb Haemost 2009;7:1737-1740.

-14 Rand JH, Wu X-X, Lapinski R, van Heerde WL, Reutelingsperger CP, Chen PP, Ortel TL: Detection of antibody-mediated reduction of annexin A5 anticoagulant activity in plasmas of patients with the antiphospholipid syndrome. Blood 2004;104:2783-2790.
5 de Laat B, Wu XX, van Lummel M, Derksen $\mathrm{RH}$, de Groot PG, Rand JH: Correlation between antiphospholipid antibodies that recognize domain I of beta2-glycoprotein I and a reduction in the anticoagulant activity of annexin A5. Blood 2007;109:1490-1494.

16 Cox RW: AFNI: Software for analysis and visualization of functional magnetic resonance neuroimages. Comput Biomed Res 1996;29:162-173.

17 Lao Z, Shen D, Liu D, Jawad A, Melhem ER, Launer LJ, Bryan RN, Davatzikos C: Computer-assisted segmentation of white matter lesions in 3D MR images, using support vector machine. Acad Radiol 2008;15:300-313.

18 Hsieh FY, Block DA, Larsen MD: A simple method of sample size calculation for linear and logistic regression. Stat Med 1998; 17: 1623-1634.

19 Brey RL, Muscal E, Chapman J: Antiphospholipid antibodies and the brain: a consensus report. Lupus 2011;20:153-157.

20 Metz LM, Edworthy S, Mydlarski R, Fritzler MJ: The frequency of phospholipid antibodies in an unselected stroke population. Can J Neurol Sci 1998;25:64-69.

21 The APASS Investigators: Antiphospholipid antibodies and subsequent thrombo-occlusive events in patients with ischemic stroke. JAMA 2004;291:576-584.

-22 Tektonidou MG, Varsou N, Kotoulas G, Antoniou A, Moutsopoulos HM: Cognitive deficits in patients with antiphospholipid syndrome: association with clinical, laboratory, and brain magnetic resonance imaging findings. Arch Intern Med 2006;166:2278-2284.

-23 Westerman EM, Miles JM, Backnova M, Sundst W: Neuropathologic findings in multi-infarct dementia associated with anticardiolipin antibody. Arthritis Rheum 1992; 35:1038-1041. 
-24 Ford SE, Kennedy L, Ford PM: Clinicopathologic correlations of antiphospholipid antibodies. An autopsy study. Arch Pathol Lab Med 1994;118:491-495.

-25 Menon S, Jameson-Shortall E, Newman SP, Hall-Craggs MR, Chinn R, Isenberg DA: A longitudinal study of anticardiolipin antibody levels and cognitive functioning in systemic lupus erythematosus. Arthritis Rheum 1999;42:735-741.

26 Hanly JG, Hong C, Smith S, Fisk JD: A prospective analysis of cognitive function and anticardiolipin antibodies in systemic lupus erythematosus. Arthritis Rheum 1999;42: 728-734.
27 Tanne D, Katzav A, Beilin O, Grigoriadis NC, Blank M, Pick CG, Landenberg P, Shoenfeld Y, Chapman J: Interaction of inflammation, thrombosis, aspirin and enoxaparin in CNS experimental antiphospholipid syndrome. Neurobiol Dis 2008;30:56-64

28 Cederholm A, Svenungsson E, Jensen-Urstad K, Trollmo C, Ulfgren AK, Swedenborg J, Fei GZ, Frostegård J: Decreased binding of annexin $\mathrm{V}$ to endothelial cells: a potential mechanism in atherothrombosis of patients with systemic lupus erythematosus. Arterioscler Thromb Vasc Biol 2005;25:198-203.
29 Valdés-Ferrer SI, Vega F, Cantú-Brito C, Ceballos-Ceballos J, Estañol B, García-Ramos G, Cabral AR: Cerebral changes in SLE with or without antiphospholipid syndrome. A case-control MRI study. J Neuroimaging 2008;18:62-65.

30 Katzav A, Faust-Socher A, Kvapil F, Michaelson DM, Blank M, Pick CG, Shoenfeld Y, Korczyn AD, Chapman J: Antiphospholipid syndrome induction exacerbates a transgenic Alzheimer disease model on a female background. Neurobiol Aging 2011;32:272279. 